\title{
Entre el goce y el padecimiento. Movilidad cotidiana y disfrute por parte de estudiantes de educación superior que habitan el periurbano de la Región Metropolitana de Santiago, Chile*
}

In the midst of Joy and suffering. Daily mobility and urban enjoyment by higher education students living in the peri-urban area of the Metropolitan Region of Santiago, Chile

\author{
María José Martínez Leiva ${ }^{\mathrm{a}}$ Alejandra Rasse ${ }^{\mathrm{a}}$
}

Historial del artículo

Recibido:

15 de septiembre 2019.

Aceptado:

29 de noviembre de 2019. a Pontificia Universidad Católica de Chile, Santiago, Chile. Correo electrónico: alejandrarasse@gmail.com

* Este trabajo forma parte del FONDECYT Regular No 1171184: "Segregaciones: habitar la periferia popular en Santiago, Concepción y Talca", y contó con el apoyo del FONDAP Centro de Desarrollo Urbano Sostenible (CEDEUS).

\section{Palabras clave}

Desigualdad urbana, expansión urbana, juventud, movilidad cotidiana

\section{Keywords}

Daily mobility, urban inequality, urban sprawl, youth

\begin{abstract}
Resumen
La oferta de educación superior en la Región Metropolitana de Santiago de Chile se localiza casi en su totalidad ( $99,9 \%$ de los programas educativos) en las treinta y cuatro comunas que conforman la ciudad compacta, y dentro de esta, casi el $70 \%$ se concentra en cuatro comunas del centro oriente de la ciudad. Esto obliga a los jóvenes que habitan zonas periféricas y periurbanas de Santiago, y que siguen estudios superiores, a desarrollar hábitos de movilidad urbana de alta intensidad y frecuencia con el centro de la ciudad. Si bien para el caso de los trabajadores que experimentan condiciones similares de movilidad se ha documentado una pérdida de su vida social, no hay evidencia respecto a cómo esta experiencia de movilidad en jóvenes que experimentan una etapa de cambio en sus comportamientos de viaje (desde movilidades intracomunales hacia movilidades de escala ciudad) influye en la forma en que experimentan la ciudad y el disfrute de su tiempo libre en ella. Este trabajo se hace cargo de profundizar específicamente sobre ese punto. A partir de la aplicación de entrevistas episódicas, cartografías sociales y recorridos acompañados, los resultados muestran que, para estos jóvenes, el ingreso a estudios superiores significa un cambio a nivel hábitos de movilidad con fuertes repercusiones en su vida familiar y social, que no fueron previstos por ninguno de ellos al ingresar a la educación superior. Se concluye que, para estos jóvenes estudiantes que habitan en la periferia y periurbano de Santiago de Chile, la exigencia espacio temporal que les impone el acceso a la educación superior propicia una fragmentación de su vida social.
\end{abstract}

\begin{abstract}
The higher education provision in Chile's Metropolitan Region is located almost entirely $(99,9 \%)$ in the thirtyfour municipalities that form the compact city. Within this supply, almost $70 \%$ is located in 4 municipalities, which are in the east part of the city. That forces young inhabitants of suburbs and periurban zones of Santiago to develop intense and frequent urban mobility among their localities and -far located- educational centres. There is some evidence about loss of social life in workers with similar urban conditions, but there is no evidence about how this experience may affect young people free time and uses of the city (considering they are experiencing strong changes in their mobility patterns, from local to urban scale mobility). Through episodic interviews, social cartography and shadowing, this paper addresses that issue. Results show that when young people start higher education, their mobility habits change generating unexpected repercussions in their familiar and social life. The paper concludes that periurban students are subject to a strong temporal-space pressure, which finally promotes fragmentation of their social life.
\end{abstract}




\section{Introducción}

La movilidad urbana en ciudades socioespacialmente segregadas plantea desventajas para aquellos grupos que inician y finalizan sus movilidades desde las áreas de expansión urbana y que dependen del sistema público de transporte para hacerlo (Andreasen \& Møller-Jensen, 2017; Apaolaza et al., 2016; Calonge, 2017; Martínez, Hodgson, Mullen \& Timms, 2017). Esas desventajas involucran: una inversión de tiempo mayor al que invierten los grupos que se mueven desde áreas centrales; una oferta restringida en términos de recorridos para salir de sus territorios a otros donde están sus áreas de interés; y largos trayectos a realizar, dado que los servicios de la ciudad se concentran en el centro y pericentro, lo que aporta a construir experiencias de movilidad urbana asociadas al agotamiento, al disgusto y a la injusticia (Iturra \& Jirón, 2016).

Esas desventajas sitúan a la movilidad urbana como una experiencia que va más allá del solo hecho de trasladarse de un lugar a otro de la ciudad (Cresswell, 2010), en ella se integran como un continuo todas las prácticas y adecuaciones de la vida cotidiana, como también las experiencias de las personas para acceder a las áreas de la ciudad que estiman necesaria o deseadas. En ese sentido, la movilidad es un proceso en que se produce la experiencia de habitar la ciudad, refiere a cómo se vive en la ciudad y a la equidad en el acceso a ella (Guzmán, Oviedo \& Rivera, 2017; Jirón, 2017).

La ciudad influye en cómo se organiza la vida de quienes la habitan (Flores, 2006), porque la organización y disposición de las oportunidades urbanas son las que dan origen y sentido a la apropiación de ella a partir de la movilidad (Blanco, Bosoer \& Apaolaza, 2014). Las formas en que las ciudades latinoamericanas se han construido y expandido en sus límites, en su mayoría han estado vinculadas fundamentalmente al desarrollo privado, con ausencia de una visión de Estado que promueva un proyecto que garantice el acceso y disfrute a esas oportunidades (Janoschka, 2002).

Por esta forma de concebir a las ciudades es que las oportunidades asociadas a la educación o al empleo se han concentrado geográficamente en las áreas centrales y pericentrales de la ciudad; mientras que las zonas de residencia de los grupos medios y populares se han ubicado con mayor densidad en la periferia y extraperiferia del área urbana (Mansilla, 2018) donde quedan desprovistos de esas redes de oportunidad. Este fenómeno es el que ha sido documentado como geografías de oportunidad desigualmente distribuidas (Millán, 2010).
Ante este escenario, los grupos ubicados en el periurbano establecen relaciones de dependencia con el centro razón por la cual la movilidad urbana adquiere especial relevancia. Así, movilidad urbana se ha vinculado con la propia capacidad de los sujetos y sus grupos familiares de comprender esa distribución de las oportunidades y desarrollar competencias para acceder a ellas (Landon, 2013).

En el contexto del acceso de los grupos familiares a las oportunidades asociadas a la educación, se ha indagado sobre las motivaciones por las cuales las familias seleccionan las escuelas de sus niños más cerca o lejos de su lugar de residencia (Córdoba, 2014; Elacqua \& Fabrega, 2004) y, más incipientemente, a la descripción de los patrones de movilidad cotidiana intercomunal de los estudiantes (Córdoba, Farris \& Rojas, 2017).

Donoso-Díaz \& Arias-Rojas (2013), a partir del análisis del registro de matrículas del sistema escolar en Chile, describen tres fenómenos asociados a la movilidad cotidiana de los estudiantes del ciclo básico y medio a nivel nacional. La movilidad de los estudiantes en Chile es mayor en educación media si se la compara con la movilidad de estudiantes de educación básica; que los estudiantes de colegios subvencionados tienen mayor movilidad hacia sus colegios que los estudiantes de colegios de administración municipal, vale decir, los colegios de administración privada atraen y concentran en mayor proporción a estudiantes de otras comunas comparado con los colegios de administración municipal; y que en la Región Metropolitana la tasa de movilidad urbana de estudiantes es superior, por sobre el resto del país. Si se observa comparativamente las comunas al interior de la región, las comunas de Santiago Centro y Providencia presentan un fenómeno único de sistemas de educación municipal "deslocalizados", en que su matrícula se compone por una alta presencia de estudiantes provenientes de comunas del periurbano.

Si se considera esa deslocalización de la matrícula, es razonable pensar que ella puede estar presente también en el nivel superior de educación, dado que este nivel educativo está conformado en su mayoría por organizaciones privadas. Al observar los registros del Servicio de Información de Educación Superior (SIES) sobre los proveedores de programas de educación superior en la Región Metropolitana, el $88,8 \%$ corresponde a instituciones privadas y el $11,2 \%$ a instituciones públicas (MINEDUC, 2018).

A partir de esto es que el análisis de la movilidad urbana para los jóvenes de educación superior, en el marco de una ciudad en que las oportunidades están desigualmente 
Tabla 1

Distribución programas de estudio y entidades de educación superior acreditadas en la Región Metropolitana.

\begin{tabular}{|c|c|c|c|c|}
\hline & Comuna & Programas & $\%$ Programas & $\begin{array}{l}\text { Instituciones ed. } \\
\text { Superior }\end{array}$ \\
\hline 1 & Santiago & 3680 & 47,3 & 58 \\
\hline 2 & Providencia & 985 & 12,7 & 21 \\
\hline 3 & Las Condes & 696 & 8,9 & 11 \\
\hline 4 & Estación Central & 366 & 4,7 & 3 \\
\hline 5 & Macul & 315 & 4 & 6 \\
\hline 6 & San Joaquín & 264 & 3,4 & 7 \\
\hline 7 & Maipú & 233 & 3 & 7 \\
\hline 8 & Ñuñoa & 188 & 2,4 & 10 \\
\hline 9 & Puente Ato & 158 & 2 & 5 \\
\hline 10 & San Bernardo & 132 & 1,7 & 3 \\
\hline 11 & Recoleta & 121 & 1,6 & 3 \\
\hline 12 & Huechuraba & 95 & 1,2 & 2 \\
\hline 13 & Peñalolén & 87 & 1,1 & 3 \\
\hline 14 & La Florida & 78 & 1 & 3 \\
\hline 15 & Melipilla & 80 & 1 & 4 \\
\hline 16 & Renca & 79 & 1 & 5 \\
\hline 17 & Buin & 38 & 0,5 & 2 \\
\hline 18 & San Miguel & 40 & 0,5 & 2 \\
\hline 19 & Cerrillos & 31 & 0,4 & 1 \\
\hline 20 & Conchalí & 28 & 0,4 & 2 \\
\hline 21 & Vitacura & 34 & 0,4 & 4 \\
\hline 22 & El Bosque & 21 & 0,3 & 1 \\
\hline 23 & Quilicura & 22 & 0,3 & 1 \\
\hline 24 & Colina & 7 & 0,1 & 1 \\
\hline \multirow[t]{2}{*}{25} & Lo Barnechea & 5 & 0,1 & 1 \\
\hline & Totales & 7783 & $100 \%$ & \\
\hline
\end{tabular}

Fuente: Servicio de Información de Educación Superior (SIES) (2018). distribuidas, tendría vínculos con las dinámicas de exclusión social, puesto que residir en el periurbano se traduce en una menor accesibilidad a centros de formación, y, en la medida que logran acceder, el tiempo destinado para su movilidad puede ser incluso el doble si se le compara con la de los jóvenes que residen en áreas pericentrales y menos vulnerables de la ciudad (Hernández, 2018).

A pesar de la relevancia de lo mencionado para el análisis de la desigualdad y exclusión social, son pocos los estudios que abordan la movilidad de los jóvenes hacia establecimientos de educación superior. Para el caso de Chile, esto resulta llamativo tanto por la proporción que representan los jóvenes que siguen estudios superiores, como también por las características territoriales de la oferta de educación superior. Según datos de la Encuesta de Caracterización Socioeconómica Nacional (CASEN) sobre la tasa de asistencia a programas de estudios de nivel superior de jóvenes entre dieciocho a veinticuatro años, se ha evidenciado un incremento de la presencia de jóvenes desde el año 1992 (12,7\%), que llega en su última medición a un 37,4\% (CASEN, 2017). Esta apertura en el acceso contrasta, sin embargo, con la concentración de la oferta de educación superior, que en casi un $70 \%$ se concentra en el centro y centro oriente de la ciudad de Santiago (Tabla 1).

Al mismo tiempo, la Tabla 1 muestra que en la mitad (veintisiete) de las comunas de la Región Metropolitana no existen entidades públicas o privadas que ofrezcan programas de estudios superiores, Melipilla es la única comuna con oferta de educación superior fuera de la ciudad compacta (figura 1). Por ende, los jóvenes que viven en

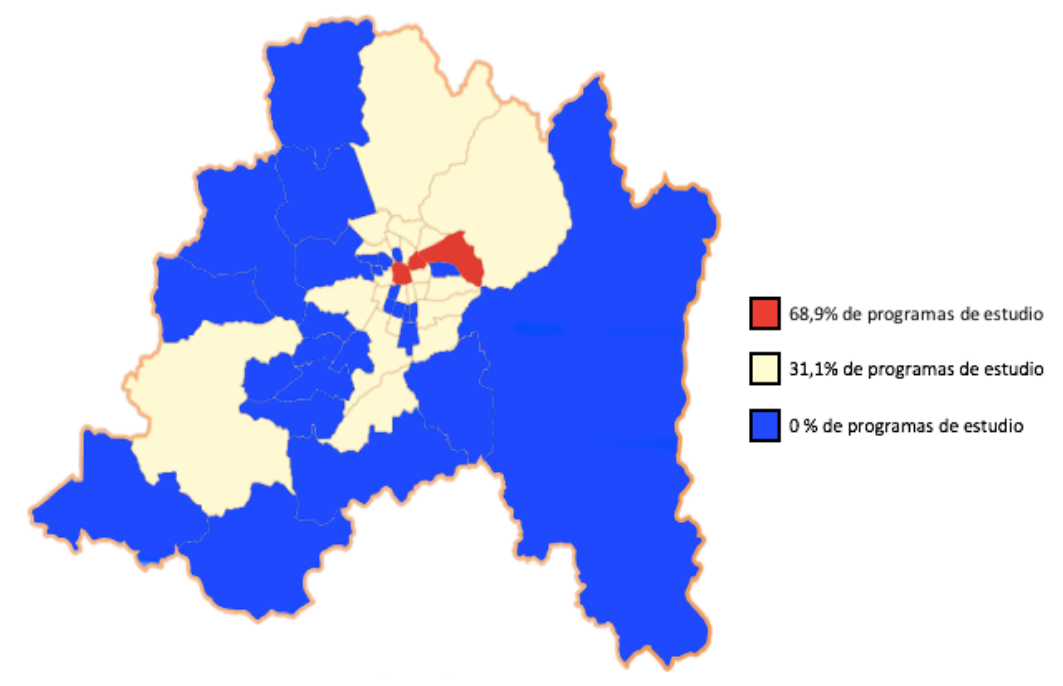

Figura 1. Distribución de los programas de estudios superiores en la Región Metropolitana de Santiago. Fuente: Elaboración propia con base en datos del Servicio de Información de Educación Superior SIES 
áreas periurbanas o de expansión urbana reciente, al finalizar su enseñanza obligatoria, deben salir de sus comunas para acceder a educación superior. La movilidad urbana y los efectos que tiene el cambio de hábitos de movilidad por el cambio en el ciclo educativo ha sido objeto de análisis en los estudios que incorporan la noción de biografías de movilidad, los cuales estudian los comportamientos de viajes durante el curso de la vida y aquellos "eventos clave" que propician el cambio en esos comportamientos (Döring, Albrecht, Scheiner \& Holz-Rau, 2014).

Los eventos clave implican la interrupción de los hábitos de movilidad por un motivo particular y están asociados a la percepción subjetiva de quienes viajan por la ciudad. Los motivos por los que las personas o grupos familiares modifican sus hábitos de movilidad están asociados al cambio residencial de los grupos familiares, al inicio, cambio y término de estudios, al inicio, cambio y término de la vida laboral y a la modificación de la cantidad de integrantes de los grupos familiares (Müggenburg, BuschGeertsema \& Lanzendorf, 2015).

Las transformaciones en los hábitos de movilidad a partir de los eventos clave se asocian a la noción de "ventana de oportunidad", vale decir, es una oportunidad para la integración de estrategias de movilidad urbana más sustentables en términos de emisiones (De Haas, Scheepers, Harms \& Kroesen, 2018).

La posibilidad de que los eventos clave constituyan no solo una oportunidad para movilidades urbanas más "verdes", sino que también más justas, implica incorporar en el análisis la percepción del viajero o commuter; este elemento ha sido considerado particularmente por las aproximaciones cualitativas a las biografías de movilidad (Sattlegger \& Rau, 2016), pues permiten profundizar en las condiciones sociales en que se desarrollan las prácticas de movilidad a través de las historias narradas por los sujetos. Resulta interesante que, en la medida de que la movilidad y los eventos clave en las trayectorias de vida de las personas aumenten, los riesgos asociados a la exclusión social disminuirían.

Al aplicar lo anterior al caso de los jóvenes de sectores periféricos y periurbanos, el ingreso a la educación superior, como evento clave en su biografía de movilidad, nos lleva a la reflexión respecto a (i) la sustentabilidad de las movilidades cotidianas que se producen, y (ii) la experiencia de viaje y de vida urbana que están teniendo los jóvenes, en el marco de su derecho ciudadano del uso de la ciudad (Hernández, 2012).
Esas experiencias de movilidad para el acceso a las oportunidades de la vida urbana -entendido como el acceso a trabajo, estudio, salud, vida familiar, ocio, cultura, etcétera-, se traducen para quienes habitan en áreas del periurbano como una pérdida sistemática de la vida social, porque el tiempo empleado en los trayectos corresponde a una transferencia del tiempo diario de otras actividades, como el ocio, la socialización con pares y las interacciones con la familia (Delclòs-Alió \& MirallesGuasch, 2017); o porque el tiempo destinado para estas actividades menos funcionales se fusiona con el tiempo laboral (Imilan, Jirón e Iturra, 2015).

Blanco \& Apaloza (2017) describen y analizan, a partir de las estrategias de movilidad cotidiana, los procesos de pérdida sistemática de la vida social de quienes habitan en zonas periurbanas, pues enfatizan en que los territorios con bajo potencial de inclusión incrementan los procesos de exclusión social, lo cual puede ser valorado con mayor intensidad en jóvenes que están en procesos de inclusión a la vida social de la ciudad.

Las reflexiones sobre la movilidad urbana para el acceso a las oportunidades y goce de la vida urbana han sido abordadas con especial énfasis en residentes de áreas centrales o pericentrales de las ciudades en Latinoamérica (Cosacov, 2015), lo que no deja de llamar la atención en la medida de que la accesibilidad al disfrute de la ciudad se traduce en exclusión precisamente para quienes habitan en las áreas periféricas o periurbanas (Mansilla, 2018).

Sobre este tema en particular, se ha planteado que aquella movilidad dirigida al goce y disfrute de la vida urbana (desplazamiento asociados al consumo, la recreación y prácticas de socialización) en la ciudad es más bien una movilidad extracotidiana (Gouëset, Demoraes, Le Roux, Figueroa \& Zioni, 2015), ya que frente a los viajes asociados al trabajo o al estudio -lo cotidiano-, la movilidad para el goce y disfrute es menos frecuente o habitual. Sin embargo, en los habitantes de las zonas centrales y pericentrales de la ciudad aparecen solapadas a las estrategias de movilidad "esencial", estrategias para acceder a las oportunidades urbanas asociada al disfrute (Blanco, Bosoer \& Apaolaza, 2014), por lo que no es evidente que el disfrute corresponda a movilidades extracotidianas, sino que más bien su frecuencia dependerá de las condiciones contextuales (que dificultan o facilitan incorporar el ocio y el disfrute en la vida cotidiana), muchas de ellas dependientes de la estructura de la ciudad y de la localización de los sujetos. 
En este marco, este estudio se propone como objetivo general comprender las percepciones sobre el acceso y disfrute de la vida urbana desde las experiencias de movilidad urbana de estudiantes de educación superior que habitan el periurbano de la Región Metropolitana. Para ello, se caracterizan los repertorios de prácticas de movilidad urbana de estudiantes de educación superior que habitan el periurbano segregado de la Región Metropolitana; se describen las transformaciones en los hábitos de movilidad urbana para el acceso a las oportunidades de estudiantes de educación superior que habitan el periurbano segregado de la Región Metropolitana; $\mathrm{y}$, se analizan los significados atribuidos al disfrute de la ciudad estudiantes de educación superior que habitan el periurbano segregado de la Región Metropolitana.

Se entiende que si bien el contexto urbano (localización, sistema de transporte, etc.) que enfrentan estos jóvenes es equivalente al de los adultos (y por ende, podría pensarse que con ellos ocurrirá lo mismo), las características propias de la etapa vital, así como las diferencias en términos de organización temporal entre el trabajo y el estudio (tiempos muertos entre clases y necesidad de estudiar, versus jornada laboral), pueden generar diferencias o matices entre sus experiencias de movilidad.

Esta problemática se funda en la intersección entre el enfoque de movilidad y los estudios de juventudes.

\section{El enfoque de la movilidad y el derecho a la movilidad justa}

El enfoque de la movilidad observa las prácticas cotidianas de los sujetos en movimiento, en él se constata que la vida es experimentada como un continuo entre los territorios (Imilan \& Jirón, 2018), lo que otorga así un nuevo marco de referencia al análisis que piensa las prácticas cotidianas situadas en un tiempo y espacios estáticos.

Cresswell (2010) desarrolla una aproximación de la movilidad urbana más allá del movimiento de un punto al otro en el espacio urbano, ya que eso es solo una de las dimensiones comprendidas en la movilidad, pues a ella se le debe incorporar el sentido y la práctica de la movilidad. El primero de ellos apunta a la dimensión relacional, que aborda las percepciones sociales y de la sociedad que se moviliza, y las prácticas refieren al sentido de las actividades cotidianas particulares de movilidad. Siguiendo a Jirón \& Lange (2017), la movilidad urbana en los sujetos se compone por todas aquellas condiciones materiales, simbólicas, expresadas, sentidas, interpretadas, proyectadas antes, durante y después del transitar por la ciudad para la realización de los proyectos de vida, del encuentro con otros.

La movilidad urbana puede ser pensada también como movilidad compartida (Verlinghieri \& Venturini, 2018), vale decir, la experiencia compartida de habitar la ciudad en movimiento "ofrece [a los sujetos] oportunidades para relacionarse con los demás, reconociendo lo común, lo compartido, lo colectivo en la experiencia de vivir en la ciudad"' (Nikolaeva et al., 2018, p.15). La movilidad urbana comprendida como movimiento común, sentido común y práctica común permite indagar en las experiencias compartidas de movilidad en categorías sociales que experimentan colectivamente las dificultades y facilitadores para el acceso a los territorios de la ciudad.

Es posible analizar la movilidad desde las nociones de derecho a la ciudad y, más específicamente, derecho a la movilidad. El derecho a la ciudad corresponde a la capacidad de creación y transformación del espacio de la ciudad que tienen sus habitantes por el solo hecho de habitar ahí. Harvey (2013) precisa que no es una capacidad contenida en los sujetos individualmente, sino que "supone reivindicar algún tipo de poder configurador del proceso de urbanización, sobre la forma en que se hacen y rehacen nuestras ciudades" (Harvey, 2013, p. 21); ese poder configurador es necesariamente colectivo porque es en el colectivo en que la ciudad es producida, apropiada, pensada e imaginada. Siguiendo a Velázquez (2018), la noción de derecho a la movilidad llama la atención respecto a que la capacidad de habitar la ciudad no solo está asociada a la posibilidad crear y recrear el territorio de las personas, sino que también al ejercicio de moverse por todo el espacio urbano para acceder a los distintos territorios de la ciudad.

El derecho a la movilidad se compone de dos dimensiones, la primera corresponde al ámbito colectivo en que la ciudadanía es provista por el Estado de un sistema de movilidad sostenible y equitativo en la distribución del equipamiento para moverse por la ciudad, y así garantizar las condiciones para moverse por el área urbana; y la otra corresponde al ámbito subjetivo de la movilidad en que es considerado el acceso de los ciudadanos a las oportunidades y la interacción social de la vida urbana (Velázquez, 2018), vale decir, cuántas de las oportunidades que la ciudad produce para el desarrollo y la interacción social pueden ser consideradas como parte de las posibilidades disponibles para sus habitantes. El ámbito subjetivo de la movilidad implica no solo el traslado de un punto a otro

${ }^{1}$ Traducción propia. 
en el espacio geográfico, sino que también involucra cómo las personas se perciben en el espacio urbano y acceden a la satisfacción de sus necesidades y deseos.

El riesgo de la denegación del derecho a la movilidad es la exclusión de la movilidad, por la cual se impide la participación "en la vida económica, política y social de la comunidad debido a la menor accesibilidad a oportunidades, servicios y redes sociales, debido en todo o en parte a la movilidad insuficiente en una sociedad y un entorno construido" (Kenyon, Lyons \& Rafferty, 2002, p. 211); los ciudadanos son marginados de la participación de la vida social a partir de que la ciudad no provee la condiciones para su participación, por lo que queda a su capacidad individual el acceder a las oportunidades.

\section{Los procesos y transiciones en la juventud}

La categoría juventud es un constructo eminentemente social, su forma y contenido están determinados y situados en un tiempo-espacio en específico que dota de sentido tanto la categoría misma como las acciones desarrolladas por quienes experimentan esta etapa de la vida. Lo relevante de ese proceso de transiciones, en las sociedades contemporáneas, no está necesariamente en el análisis aislado de las acciones o decisiones que toman los jóvenes sobre sí mismos, sino más bien cómo esas decisiones dialogan entre sí y el tiempo-espacio en que ellos viven crea una pluralidad de trayectorias que se manifiestan en términos del grupo social al que pertenecen, las biografías y trayectorias vitales en el paso hacia la adultez, entre otros aspectos (Solanilla, 2007).

Aquellas trayectorias de transición en los jóvenes están determinadas por las transformaciones que emergen durante el fin de procesos de formación como personas autónomas y respecto de sus grupos familiares; así, se concibe a la juventud como un tránsito hacia la adultez, la cual se constituye a partir de decisiones individuales y estructurales de la propia vida (Brunet \& Pizzi, 2013), vale decir, como el estado en que las personas alcanzan su "madurez social" (Urcola, 2003).

La trayectoria biográfica de los jóvenes permite hacer una lectura comprensiva de esas transiciones, y su diversidad o pluralidad interpretada como parte del proceso de desestructuración de la herencia social en la que los grupos familiares podían ofrecer a sus integrantes más jóvenes la herencia ocupacional que garantiza la estabilidad del patrimonio material y simbólico. En el contexto sociohistórico actual, las familias no son capaces de ubicar a los miembros más jóvenes con el mismo nivel de arraigo social y estabilidad ocupacional en la que ellos están (Gil, 2009), de ahí que la integración y madurez social de los jóvenes más vulnerables dependa de su propia capacidad. Para muchos jóvenes de grupos medios y -especialmente- populares, el ingreso a la educación superior es experimentado por primera vez en la familia, en ese sentido en ellos se "cristaliza este desajuste, en la medida que inician trayectorias y transiciones (hacia la adultez y la integración) en un nuevo contexto de incertidumbre y desamparo social; no hay aún una memoria social para responder a los nuevos desafíos" (Saraví, 2006, p. 111), son los jóvenes quienes deben aprender por sí mismos a construir su biografía y enfrentar los desafíos que ello supone.

\section{Metodología}

Para lograr el objetivo planteado, se desarrolló un estudio cualitativo de ocho casos de jóvenes de las comunas de Lampa y Quilicura, actualmente estudiantes en universidades o institutos profesionales de la Región Metropolitana. Se decide trabajar con Lampa y Quilicura por corresponder ambas a comunas de la Región Metropolitana que han experimentado procesos recientes de urbanización, principalmente a partir de mecanismos de desarrollo urbano condicionado fuera del límite urbano de la ciudad. De acuerdo a datos censales, Lampa es la comuna con mayor aumento de población en los últimos quince años (155\% de aumento 2002-2017), y Quilicura la cuarta (647\% de aumento 2002-2017). Al mismo tiempo, ambas representan condiciones diferentes: mientras Quilicura hace parte del sistema integrado de transporte metropolitano, Lampa queda más distante y depende de transporte interurbano (figura 2).

Para la elección de los jóvenes, se realizó un muestreo intencionado (Flick, 2007), focalizado en estudiantes sin hijos, de entre veinte y veintinueve años, en programas con régimen de estudios presencial en universidades o institutos profesionales ubicados en el centro de Santiago, y cuyo principal medio de transporte sea el sistema público. Estas características buscaron aproximarse al perfil más habitual de estudiantes e instituciones educacionales, de acuerdo al Sistema de Información de Educación Superior (SIES, 2017). Se buscó, adicionalmente, tener una distribución de género equitativa en la muestra. Con esto, la muestra quedó constituida por ocho jóvenes, cuatro hombres y cuatro mujeres, tres de los cuales vivían en Lampa, y cinco en Quilicura.

Con cada uno de estos jóvenes se aplicaron dos técnicas: una entrevista abierta basada en un ejercicio de mapeo y un recorrido acompañado o "sombreo". 


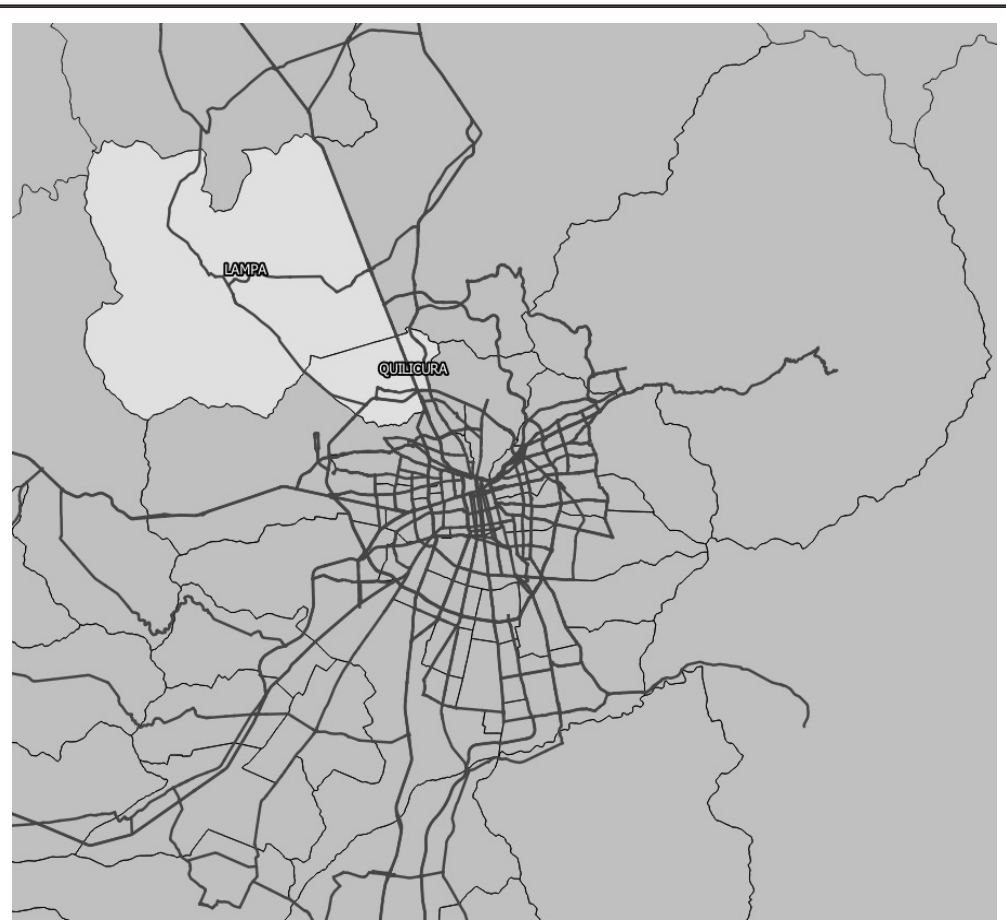

Figura 2. Localización de las comunas de Lampa y Quilicura en la Región Metropolitana de Santiago, y red de autopistas y vialidad estructurante. Fuente: Elaboración propia.

La entrevista consistió en una conversación abierta, focalizada en la narración y descripción de las movilidades de cada joven, de los cambios experimentados en sus movilidades al ingresar a la educación superior $\mathrm{y}$, a partir de eso, su apreciación sobre su barrio y la ciudad, y sus expectativas, deseos e intereses tanto para los días de semana como en los fines de semana. Este ejercicio se apoyó en el dibujo de una cartografía de movilidades de cada joven, para lo cual fueron impresos mapas a gran escala de las comunas y la Región Metropolitana, donde cada joven identificó los puntos en que inician y finalizan sus movilidades, lugares visitados y de interés. La elaboración de los mapas se reporta como insumo para el análisis de sus prácticas de movilidad y los repertorios desplegados para disfrutar de ella.

El recorrido acompañado consistió en la realización del viaje cotidiano desde y hacia el establecimiento de educación superior en compañía de los jóvenes. Esta técnica permite integrar el relato narrado con la observación, para dar soporte y contexto a esa narrativa. Su principal ventaja es que en esta técnica los participantes del estudio no solo describen los lugares o situaciones que le afectan, sino que también pueden mostrarlas, reflexionar e indagar en aspectos no evidentes para ellos (Clark \& Emmel, 2010). Además, el recorrido acompañado permite integrar al proceso de recogida de datos la posibilidad de ocurrencia de imprevistos y aspectos contingentes que solo en las estrategias de movilidad in situ pueden ser experienciadas, lo que a su vez hace plausible a los participantes organizar sus propias ideas asociadas a lo narrado (Clark \& Emmel, 2010), por lo tanto, lo construido de ese acompañar a los participantes es tanto la identificación de sus hábitos de movilidad urbana como también el compromiso de inmersión en su cosmovisión de la ciudad y sus prácticas de movilidad urbana (Büscher \& Urry, 2009).

Adicionalmente, con posterioridad a la entrevista con cartografía y al recorrido acompañado, con cada joven se realizó un encuentro de cierre, en el cual se consultó sobre algunas dudas surgidas en el análisis y se validaron las interpretaciones realizadas.

Siguiendo a Cornejo, Mendoza \& Rojas (2008), el análisis de los datos se realizó en dos etapas. En un primer momento, se realizó un análisis intracaso, que identifica los hitos del relato reconstruido, en el cual se utiliza la técnica de codificación abierta; en un segundo momento, se trabaja de forma transversal donde se analizan los distintos relatos, se identifican las continuidades y discontinuidades entre ellos, para aplicar codificación temática. 
Las historias que fueron parte del análisis son presentadas con nombres ficticios -creados por el equipo investigadorpara resguardar la real identidad de los participantes.

\section{Resultados: cuatro historias de movilidad}

A continuación, se presentan cuatro de las ocho historias de movilidad desarrolladas por este estudio.

\section{Romina}

Romina tiene veinte años y vive desde hace dos años junto a sus tíos en un condominio cerrado de estratos medios en Quilicura. Antes de eso, había vivido toda la vida en casa de su abuela, en la comuna de Conchalí.

Durante toda su enseñanza media, Romina asistió a clases a un colegio ubicado en la misma comuna, solo a algunas cuadras de la casa de su abuela. Para llegar, caminaba algunos minutos hasta llegar a una avenida troncal y ahí subía a cualquier microbús que pasara en dirección norte. Cuando Romina estaba atrasada para ir a clases (a las ocho de la mañana), era su tía quien la iba a dejar en auto, lo que podía demorar como máximo quince minutos. En ese sentido, el cómo llegar a clases o el tiempo que eso le podía tomar no era una preocupación para ella durante su enseñanza media.

Respecto a su barrio en Conchalí, Romina recuerda que le ofrecía múltiples actividades asociadas al disfrute de su tiempo fuera del colegio y múltiples modos de acceso. Pasear por su barrio era una de ellas, ya que haber vivido siempre en el mismo lugar le permitió conocer a todos los vecinos de su cuadra y a los jóvenes de los alrededores. Este punto en particular lo compara con la relación con sus vecinos en su nuevo barrio, con los cuales no tiene ninguna relación, y lo añora especialmente. El punto más alejado que ella indica haber visitado con frecuencia mientras vivió en Conchalí, corresponde a un centro comercial ubicado en una comuna contigua, en un trayecto que le tomaba veinte a treinta minutos combinando bus y caminata. En él, "tenía la posibilidad de mirar las tiendas y quizás comprar algo" (Romina, comunicación personal, 2018). Visitar con su tía la feria persa, bastante cerca de su casa, constituía otro de los panoramas de los días viernes, sábado y domingo. En el persa una de sus mejores amigas tiene un puesto, por lo que ese lugar era para ella no solo un punto para satisfacer necesidades de consumo, sino también para el encuentro con amigas y conocidos. Actualmente sus visitas al persa son muy esporádicas debido a su cambio de casa, "como yo vivo en Quilicura no me paso mucho al persa porque es una lata ir allí, pero igual a veces me hago un esfuerzo y digo ¡ya, voy a verte!" (Romina, comunicación personal, 2018)

El persa y sus alrededores -comercios informales, plazas y negocios de comida rápida- son recordados con especial cariño, ya que eran espacios en que compartía con su tía y otras amigas sin mayores presiones horarias. Desde que Romina fue a vivir a Quilicura ha visto solo un par de veces a sus amistades de su antiguo barrio y ya no visita regularmente el persa.

Ella destaca que mientras vivió ahí nunca fue un problema el cómo llegar a su casa ni a otro punto dentro de su comuna, la presión del tiempo en el ámbito de su movilidad solo comenzó a ser percibida por ella cuando llegó a su nuevo barrio. Según su percepción, su barrio en Conchalí nunca dejaba de estar activo, tenía múltiples caminos para acceder a los lugares de su interés y caminar de un punto a otro era una estrategia efectiva de movilidad, por ello es que cuesta describir este aspecto con detalles, pues nunca pensó ni reflexionó mucho sobre esto.

En Quilicura, Romina tiene trayectos más fuertemente asociados a lugares que satisfacen puntualmente sus necesidades de consumo, como el centro comercial que queda en su comuna y el supermercado que se encuentra al interior de su condominio. A diferencia de los lugares de consumo en su anterior barrio, para ella estos lugares no constituyen espacios de esparcimiento propiamente tal, va para comprar y nada más. Además de estos dos lugares, el único otro lugar que ha visitado en la comuna es un restaurante de comida china al que va con su familia.

La salida más regular que mantiene hoy Romina, además de ir a clases en su centro de estudios, es a la casa de su mamá, quien vive a algunas cuadras de la casa que comparte con su tía, en un conjunto de vivienda social.

El centro de estudios de Romina está ubicado en el barrio universitario, en el centro de la ciudad. Para llegar hasta él, Romina solo puede acceder por el transporte público, combinando el metro con la única línea de microbuses que llega hasta su casa. El tramo entre su casa y la estación le toma entre treinta a cincuenta minutos considerando una caminata de cinco minutos hasta el paradero, la cual realiza disfrutando el paseo, "me tomo mi tiempo para caminar hasta llegar al paradero" (Romina, comunicación personal, 2018).

Si la llegada al metro le toma treinta minutos o más, todo dependerá del nivel de congestión con que pueda encontrarse en la autopista que permite conectar con el 
metro, y en el paradero mismo: "Hay veces que se va la micro llena, pero hay veces que se va demasiado llena, donde la gente ya no entra, entonces (...) empiezan a pasarte a llevar con los brazos, con la mochila entonces igual es como incómodo" (Romina, comunicación personal, 2018). Este recorrido en bus es la única alternativa que tiene Romina para salir de su comuna, e inclusive, para acceder al resto de la comuna, ya que su condominio se encuentra separado del resto de Quilicura por la presencia de la autopista.

Habitualmente, al llegar a la estación, Romina baja del microbús y toma el metro en dirección al centro de la ciudad. Ese tramo le toma alrededor de treinta minutos más. Ahí, camina cerca de cinco minutos hasta llegar a su lugar de estudios, por lo que su tiempo de viaje le toma alrededor de setenta minutos cuando no tiene ningún retraso. Durante el recorrido acompañado, el viaje tomó ochenta y cinco minutos.

Durante el día, Romina recorre el barrio universitario, especialmente en "las ventanas" (tiempos muertos entre clases). Ella conoce lugares donde comer por poco dinero. Pasear, comprar y descansar por el barrio lo realiza solo si tiene tiempo disponible entre clases.

Si bien en su casa no le exigen volver a cierta hora luego de estudiar, ella prefiere volver inmediatamente terminadas sus clases, esto porque así evita la hora punta en el metro y especialmente en el microbús de vuelta a su condominio. Siempre debe hacer una fila de veinte minutos para poder subir al microbús. Sobre su experiencia en el microbús, ella se siente incómoda al ir de pie, pero prefiere eso a esperar más tiempo por viajar sentada hacia su casa.

Una vez de vuelta en casa, Romina comparte la tarde con su tía. A pesar de que está cansada, intenta conversar con ella, pero preferiría no hacerlo. Comenta que a veces responde de mala manera a las preguntas de su tía y se percata que esa forma de tratarla es injusta.

Los fines de semana Romina prefiere no salir con amigas y en lugar de eso, descansar, compartir con su familia, estudiar y 'hacer nada': "hace meses que no la veo [a mi amiga] por el tema de la universidad, los horarios, los fines de semana que de repente uno igual tiene que hacer cosas, estudiar los sábados también, entonces es complicado juntarnos" ( comunicación personal, 2018). Solo sale si tiene panoramas con sus amigas del centro de estudios, y para ello siempre se queda a dormir en la casa de alguna de ellas, pues durante la noche no hay transporte público que la lleve a su condominio y los valores de taxis o aplicaciones móviles exceden su presupuesto.
Sus amigas y compañeras de clase viven en Puente Alto y en Ñuñoa, no conocía a ninguna de esas comunas antes de iniciar sus estudios en Santiago Centro. Sobre ese punto ella se percata de lo diferente que es moverse por la ciudad para su amiga que vive en Ñuñoa, "ella llega caminando para todos lados, ¡incluso una vez me hizo caminar de su casa a la universidad!" (Romina, comunicación personal, 2018), comenta con impresión ya que para ella eso no es una opción para llegar a clases.

\section{Mario}

Mario ha vivido en dos lugares distintos dentro de la comuna de Quilicura. Tres años atrás vivió en un conjunto habitacional de estratos medios ubicado en la zona nororiente de la comuna que colinda con un área industrial. Mario y su familia vivieron durante quince años en esa casa que había sido obtenida mediante un crédito hipotecario, el cual no pudieron seguir pagando y fueron desalojados. $\mathrm{Su}$ actual domicilio es en una vivienda ubicada en un conjunto de vivienda económica.

Para asistir a clases desde su antiguo barrio, Mario regularmente caminaba alrededor de veinte o veinticinco minutos desde su casa, a veces esto tomaba más tiempo si es que pasaba a buscar a una amiga. Cuando estaba atrasado, Mario caminaba hacia el paradero más próximo a su casa, a menos de cinco minutos, esperaba el microbús, y en diez minutos estaba en la puerta del colegio.

Para Mario, su barrio era un lugar muy seguro, contaba con plazas y áreas verdes equipadas con juegos y máquinas de ejercicios en las que se reunía con sus amigos dos veces por semana. Todos sus amigos vivían a pocas cuadras, por lo que para todas sus fiestas y reuniones podía trasladarse caminando. Para él, pasear hasta altas horas de la noche los fines de semana era algo habitual.

Una vez que Mario se cambió de casa e ingresó a estudiar en el centro dejó de ver regularmente a sus amigos, "con los chicos de mi barrio no hablo con nadie, a mis amigos no los veo, a los del colegio ya ni les hablo, al principio sí pero ya después no, entré acá [a estudiar] y ya nada más" (comunicación personal, 2018).

Cuando Mario y sus padres se tuvieron que cambiar de casa, él se encontraba comenzando sus estudios en el centro de Santiago. El nuevo conjunto está ubicado cerca de la principal avenida de Quilicura, sin embargo, desde que Mario vive ahí, ha estado con trabajos de ampliación, por lo que los recorridos que pasan no son los más directos y rápidos para llegar al barrio universitario, lugar en que 
está ubicado su instituto. A partir de ello es que Mario ha probado dos rutas alternativas para definir cuál de ellas le permitía pasar menos tiempo de viaje.

La primera de ellas combina una caminata de diez minutos aproximadamente hasta el paradero del recorrido $315 \mathrm{e}$. Este microbús toma una ruta al interior de la comuna que abarca gran parte del área norte/suroriente de la comuna, por lo que desde que Mario sube al microbús y este sale de la comuna, pasan cuarenta o cincuenta minutos, principalmente por la congestión vehicular al interior de la comuna en los horarios en que Mario debe ir a clases. Es por ese tiempo "perdido" que Mario decidió probar otra ruta para salir en menos tiempo.

La nueva estrategia, que es la que actualmente utiliza para salir de la comuna, combina caminata y trasbordo entre dos microbuses al interior de la comuna. Al considerar los minutos caminando al paradero, el trayecto de algunas cuadras hasta el paradero del primer microbús y el trasbordo al segundo microbús, cuyo paradero final está ubicado en Estación Central (comuna vecina al barrio universitario), su viaje le toma una hora en total. El hecho que al interior de su comuna deba hacer combinación de buses lo considera como un "mal menor" si lo compara con pasar cincuenta minutos viajando dentro de Quilicura como le ocurría con la otra alternativa.

Al bajar del microbús en Estación Central, como lo muestra el Mapa 8, camina hasta llegar a su centro de estudios. Para él, esta estrategia le permite pasar menos tiempo de viaje y le evita tomar el metro en horarios punta, ya que esto último le hace sentir ansiedad y agobio por la cantidad de personas al interior de él.

Mario con su grupo de amigos del centro de estudios pasea por el barrio universitario, pasan la tarde en el Parque Quinta Normal (también cercano al centro de la ciudad).

Para tomar un trago, Mario se reúne en los bares cercanos a su centro de estudios y solo en contadas ocasiones visita el barrio Bellavista (también muy cercano al centro de la ciudad). Mario aprovecha su día en el centro de Santiago para comprar, pasear con amigos y estudiar.

Para él, el problema de Quilicura no es la distancia con el centro, sino que el tiempo que una persona puede pasar en un microbús intentando llegar a cualquier lugar fuera de la comuna. Todos los trasbordos que se realizan durante un viaje y la preocupación por el tiempo que transcurre desde que sale de su casa hasta el lugar que desee es percibido y sentido como un gran desgaste físico y emocional. Mario cree que esto es experimentado por todos los que viven en la comuna y deben salir regularmente de ella, "entonces sí, el hecho de planificarse para salir con anterioridad, como con una hora de anticipación, es algo que sí o sí tienes que planificar, y eso yo creo que lo hacen todos en Quilicura” (Mario, comunicación personal, 2018). Piensa además que esta preocupación no es compartida por sus compañeros de curso, "mis otros amigos [de otras comunas] no tienen problemas para moverse" (Mario, comunicación personal, 2018).

En su actual barrio prefiere no realizar ninguna actividad, puesto que no conoce ni quiere conocer a nadie, sus amigos del anterior barrio también están estudiando por lo que ya no coinciden sus tiempos libres. Así que habitualmente no sale de su casa, "me quedo encerrado viendo una serie o jugando, lo que es fin de semana trato de descansar, como te digo si hay una fiesta y de hecho puede que tenga muchas fiestas no salgo, sobre todo si estoy cansado" (Mario, comunicación personal, 2018). Al pensar en el lugar en que actualmente vive no puede dejar de compararlo con el anterior. Mario nota la falta de áreas verdes en buen estado y equipamiento recreativo, los espacios públicos se mantienen sucios, con rayados y pequeños grupos de jóvenes que le dan la impresión de que "no andan en buenos pasos, por lo mismo, yo no recomendaría pasar de noche por aquí, (...) en el sector donde vivo yo no es muy bueno que digamos, de hecho andar solo de noche te puedes exponer a muchas cosas" (comunicación personal, 2018).

\section{Camila}

Camila tiene veintiún años y toda su vida ha vivido en Lampa. Hace siete años que está en su actual casa. Antes, ella con sus padres arrendaban una casa en un sector semirural de la comuna. Al momento dejar esa casa, Camila recuerda que su padre no se encontraba en condiciones económicas para pagar un arriendo en una casa en la misma localidad, por lo que un amigo de él le ofreció utilizar una vivienda de material ligero ubicada en el patio de su casa, ofrecimiento que fue aceptado y sigue siendo hasta el día de hoy su hogar.

Camila estudió su enseñanza media en Lampa. Recuerda que caminaba alrededor de treinta minutos al colegio, ya que si bien había transporte público que la dejaba en el colegio, para su familia era costoso pagar por ese transporte; la opción de pedir permiso a los choferes no existe para ella, ya que los choferes de los buses que transitan por Lampa "hacen lo que quieren, uno no puede decirles nada porque o si no te bajan, con los estudiantes sobre todo" (Camila, comunicación personal, 2018). 
A Camila le gusta vivir en Lampa, considera que lo mejor de su comuna es esa tranquilidad que solo el campo puede ofrecer y por esto caminar hacia el colegio era un paseo para ella. Los períodos de lluvia eran los más complejos en su trayecto, ya que en las primeras cuadras más próximas a su casa la calle se llenaba de barro, lo que hacía el cruce muy peligroso.

El centro de estudios al que actualmente asiste Camila se encuentra en el barrio universitario, en el centro de Santiago. Desde que Camila comenzó sus estudios superiores cree cada vez más que Lampa se ha transformado en un problema para ella, esto porque si bien sabía que Lampa se encontraba lejos del centro de la ciudad, nunca pensó lo que significaba experimentar esa distancia todos los días. Para llegar a su lugar de estudios, Camila ha probado todos los recorridos de buses disponibles. El primero de ellos es el que tiene su paradero final en el terminal de buses La Paz ${ }^{2}$. Desde ahí combinaba con el metro para llegar a su centro de estudios. Esta era la vía más directa para Camila hasta que comenzaron los trabajos de mejoramiento vial de la avenida troncal por la que circulan esos buses, lo que hacía que su viaje desde su casa hasta el metro le tomara dos horas y media aproximadamente.

Por ello es que desde ese momento comenzó a tomar un bus que viaja por la autopista y que tiene su parada final a pocas cuadras de su centro de estudios. Para asistir a clases a las ocho y media de la mañana debe salir y tomar este microbús a las seis de la mañana, por ende, a eso de las cinco de la mañana ella está preparándose para salir a clases. El lugar donde sube al microbús es la entrada de la garita, un paradero informal desde donde se inicia el recorrido, por lo que siempre puede ir sentada. Mientras viaja aprovecha ese tiempo para dormir, tomar desayuno y eventualmente estudiar.

El viaje por sí mismo para ella es agradable, ya que va sentada. Las personas que ella ha observado viajando en su bus hacen lo mismo que ella: leen, duermen o toman desayuno, salvo por quienes toman el bus en las afueras de Lampa y deben viajar de pie, uno al lado del otro, equilibrándose para no caer con las subidas y bajadas de velocidad que son recurrentes. Sobre ello Camila comenta que los choferes "andan como locos por las calles" (comunicación personal, 2018). En ese sentido, lo que realmente es un problema para ella es todo el tiempo que debe destinar para realizar sus viajes de ida y vuelta, lo que en total le toman entre cuatro y cinco horas al día, "es terrible, es horrible estar viajando siempre" (Camila, comunicación personal, 2018).

En ese sentido, tras ese desgaste físico, mental y emocional para mantener esa relación con el centro de la ciudad, Camila percibe que hay que tener una fuerza de voluntad, "no sé si hay que tener fuerza, no sé, pero para venir a pegarse el viaje todos los días, y tantos años (...) si ya aguanté todos estos años como no voy a aguantar uno más" (comunicación personal, 2018).

Desde que Camila pasa menos tiempo en su comuna durante el día, ha comenzado a sentir que su comuna se ha vuelto más peligrosa, "es terrible incluso ahora ya no se puede caminar por aquí porque está en la noche muy conflictivo, es horrible" (comunicación personal, 2018). Se ha tornado en un espacio inseguro para ella, menos rural, sobre todo en su barrio en el que se han instalado tomas de terreno "de personas de fuera, que no son de Lampa" (Camila, comunicación personal, 2018).

En los tiempos libres que pasa en Lampa, ella se queda en su casa o en la de su pololo, ya que su comuna tiene horarios de funcionamiento acotados en la mañana y en la tarde, sobre este punto ella indica: "que la gente ya se acostumbró, entonces a esa hora la gente ya no, ya no hay nada, después anda gente, regular. Es que Lampa igual es súper flojo, como que la gente, los mismos de los locales son flojos" (Camila, comunicación personal, 2018).

También ha ido un par de veces a una discoteca que está cerca de su casa, a un bar en el centro de Lampa, y cuando necesita comprar algo, se dirige al supermercado ubicado en el centro de Lampa. Estos lugares en Lampa hoy parecen no ser tan relevantes en su vida, cada vez que menciona alguno de ellos termina la frase con "tampoco es que vaya tanto, Lampa es tan chico que todo el mundo se conoce, y eso hace que el resto "cahuinee' [haga chismes]" (Camila, comunicación personal, 2018).

Después de clases por lo general se va inmediatamente a su casa, ya que siempre está pensando en que aún le quedan dos horas más de viaje, y eso la desanima a pasar parte de su tiempo libre en el centro de Santiago, "en el día igual se juntan [mis amigos] en las vacaciones, pero no. La lata es levantarse dos horas antes. Eso yo les decía a los chiquillos que no es que no quiera, es la lata del viaje, nada más que eso" (Camila, comunicación personal, 2018).

${ }^{2}$ Un terminal ubicado sobre el borde norte del centro de la ciudad, al cual llegan buses interurbanos de localidades cercanas a Santiago. 
Sus amigos habitualmente se quedan en los alrededores del centro de estudio para comer algo o salir juntos, pero ella prefiere no participar de eso, "quedarme a tomar algo y después en la micro dos horas para allá, no, horrible, no, ni cuando estoy de vacaciones me junto con ellos [en el centro] porque vivo lejos" (Camila, comunicación personal, 2018). Ella siente que a veces sus amigos no comprenden lo que para ella significa el viaje, "me dicen que solo vengo para estudiar, de mi casa a clases nada más, y ellos no entienden" (Camila, comunicación personal, 2018).

Camila se reconoce de pocas amigas y las que tiene las ve con menos regularidad desde que ingresó a estudiar en el centro de Santiago no solo por la falta de tiempo, sino también por la pérdida de temas en común que la vincule a ellas, cosas que no le suceden con sus compañeros de estudio:

Por ejemplo, hablo con mis amigas, pero de repente no me entienden lo que hablo, y hablo acá con los chiquillos y hablamos así bacán así, y yo le digo a mi pololo, porque de repente igual yo le hablo a él y no me entiende, y le explico algo y no me entiende y digo 'puta ya...' y le hablo lo mismo a mi amiga del instituto y me entiende, y hablamos. Entonces es muy diferente. Yo lo noto y él igual lo nota. (Camila, comunicación personal, 2018)

Para ella pensar en Santiago le trae sentimientos encontrados, al mismo tiempo que el centro concentra todo lo que le interesa y apasiona, "como que siempre he pensado que es como que hay más posibilidades, pero también estoy lejana a esas posibilidades" (Camila, comunicación personal, 2018). Al mismo tiempo le obliga iniciar todos sus días muy temprano con la preocupación de llegar a tiempo a otro lugar, pasar todo el día en un lugar con un ritmo distinto al de su comuna, y estar preocupada de cómo volver a su casa; "no me gusta Santiago, como estoy acostumbrada a la poca gente, no sé, al ambiente de allá" (Camila, comunicación personal, 2018).

Esa diferencia entre su comuna y el centro de Santiago se ha transformado en una dificultad percibida como la pérdida de continuidad entre ambos espacios, lo que en aspectos académicos siente que le ha jugado en contra: "como que llego a Lampa y se me olvida todo. Yo creo que no tengo con quien conversar esas cosas, como que me desligo (...). De verdad es loco. Yo creo que es por eso, porque no tengo a nadie con quien hablar de las mismas cosas que me gustan a mi" (Camila, comunicación personal, 2018).

$\mathrm{Su}$ expectativa, una vez finalizados sus estudios, es no volver más a Santiago del modo que lo ha hecho hasta ahora, tiene la convicción de que en su comuna puede encontrar trabajo en la carrera que ha estudiado, "en Lampa hay un CESFAM [centro de salud] cerca de mi casa y ahí hay una trabajadora social, yo creo que ahí puedo encontrar trabajo" (Camila, comunicación personal, 2018).

\section{Diego}

Diego hace doce años que vive en un conjunto de estratos medios en Lampa junto a sus padres y su hermana que aún cursa estudios secundarios. Asistió toda su enseñanza media al colegio en la misma comuna.

Para asistir a clases, Diego caminaba alrededor de veinte minutos. Durante ese trayecto aprovechaba para fumar unos cigarrillos, de hecho, es una costumbre que mantiene hasta ahora cuando va de camino al bus que lo trae a su centro de estudios en el barrio universitario en el centro de Santiago, "es como una tradición" (Diego, comunicación personal, 2018). Después del colegio, Diego se reunía con sus compañeros en sus casas o en la Plaza de Armas de Lampa, lugar en el que regularmente organizaban grupos para cantar Hip-Hop, o simplemente para conversar.

A Diego nunca le ha gustado vivir en Lampa. Considera que es una comuna demasiado pequeña, rural y que no se ha dado cuenta de que es parte de una ciudad como Santiago. Para él, la forma de vida de los vecinos de su comuna corresponde a una visión "limitada del lampino que ha vivido toda su vida en Lampa" (Diego, comunicación personal, 2018), que no tiene deseos de hacer nada distinto a lo que ha hecho siempre. Por ello es que cree que la llegada de nuevos vecinos a Lampa le ha venido muy bien, en especial a aquellos que han elegido vivir en Lampa, como las familias de Larapinta ${ }^{3}$, ya que "se nota que son distintos porque no están todo el día en la casa, se les ve que salen temprano a trabajar afuera" (Diego, comunicación personal, 2018).

En Larapinta existe un parque central y plazas que Diego ha usado para hacer deporte, también aprovecha de utilizar sus comercios de comida. Con su polola, quien vive en una de las zonas que considera peligrosas en Lampa, pasan gran parte de su tiempo aquí o en el centro de Santiago. Para Diego, el estudiar en Santiago centro ha sido una

${ }^{3}$ Un proyecto inmobiliario de gran escala, desarrollado bajo la figura de desarrollo urbano condicionado y orientado a familias de estratos medios. 
oportunidad que no todos los habitantes de Lampa conocen. Para él viajar no es un problema, pues sabe que al llegar al centro se encontrará con amigos, con un barrio en que todo está a la mano: comercio, entretención, áreas verdes, lo que lo hace realmente problemático es el tiempo que debe pasar en ello:

El viaje es tan largo que te cansa mentalmente, llegas cansado mentalmente, pierdes el tiempo en prepararte algo para comer [al llegar a la casa], en volver a reactivarte y empezar, como que pierdes el hilo conductor (...) siento como que tengo que reponerme de ese viaje. (Diego, comunicación personal, 2018).

Para subir al bus hacia su centro de estudios camina cinco minutos hasta el paradero, ahí pasa un recorrido que le permite combinar con el metro, en él viaja tres estaciones, y finalmente camina cinco minutos hasta su centro de estudios. En su tiempo libre en Santiago, Diego pasa la tarde en la Plaza Almagro (cercana al centro de Santiago), lugar que tiene a sus alrededores distintos centros de estudios y particular, el de su polola. Ahí comparten con amigos de ambos.

A Diego le agrada el centro, prefiere pasar la mayor parte de su tiempo libre ahí ya que siente que lo mantiene activo, a diferencia de lo que el ritmo de Lampa le puede ofrecer. A pesar de los cambios que Diego ha tenido que experimentar en su movilidad y uso de su tiempo, él no lo cambiaría para pasar más tiempo en su comuna. Sus planes a corto plazo son terminar de estudiar y salir de Lampa para aproximarse más al centro de la ciudad.

\section{Discusión}

\section{La reconstrucción del barrio y la ciudad a través de la movilidad urbana}

En todos los relatos de los jóvenes entrevistados, el ingreso a estudios superiores significa un cambio no solo a nivel hábitos de movilidad, sino toda una transformación de su vida familiar y social, en dimensiones que al momento de comenzar a estudiar no habían sido consideradas por ninguno de ellos. Sin saberlo, toman una decisión que va más allá de la definición de sus estudios, es una decisión implícita que se juega en la esfera de la vida social y tensiona las formas de habitar en la ciudad (Lazo \& Calderón, 2014).

Su barrio pasa de ser el escenario donde se desarrolla la vida con la familia y los amigos, a un espacio definido por la oposición: el lugar que condensa las diferencias respecto al centro de Santiago. Mientras en la narración de su etapa escolar se destaca el intensivo uso del espacio público barrial y comunal, al situarse en su momento actual se incorporan nuevos sentidos sobre la propia comuna que antes no estaban problematizados. Comienza a desarrollarse en estos jóvenes un sentimiento de extrañamiento respecto de su comuna y sus vecinos, y se vuelve progresivamente en contenedora de aspectos negativos, como la suciedad y poca mantención del espacio público, la acotada oferta y horarios de funcionamiento de los locales comerciales, la localización de la comuna y la percepción de un deficiente acceso al transporte público.

Antes del cambio en sus hábitos de movilidad, los jóvenes destacan no tener noción real de su ubicación respecto al centro de la ciudad, ya que no tenían la necesidad de salir de sus comunas pues sus redes significativas (amigos y familia) y su lugar de estudios se localizaban ahí. Esta concentración en la escala comunal es interesante no solo porque muestra que la vida de los habitantes de periurbano puede ser vivida en una escala local, incluso caminable, pero en ciertos momentos del ciclo vital.

El ingreso a la educación superior, y con ello, la modificación de los hábitos de movilidad, implican un cambio no solo en la escala en que los jóvenes se mueven y se representan la ciudad, sino también en la relación que establecen entre tiempo y espacio. Por su extensión y la variedad de elementos que influyen en él, resulta necesario planificar el viaje, y cada una de las actividades que le anteceden y preceden. Frente a la sobreabundancia del tiempo descrita en la etapa escolar, emerge una presión temporal, perciben la necesidad de ponderar el tiempo para realizar las actividades obligatorias, y luego evaluar si queda tiempo para algo más. Las redes localizadas en los territorios de proximidad se abandonan y aquellas que se mantienen se empobrecen tanto en intensidad como en contenido: se pierde lo común.

Todos los participantes reconocen que sus amigos hoy no están en sus comunas, no porque sus amigos se hayan ido del barrio, sino que ahora experimentan sus afectos y redes fuera de su lugar de residencia. El habitar en movimiento a escala ciudad ha diversificado sus redes con jóvenes que viven en distintos lugares, con quienes comparten temas e intereses comunes, lo cual se constituye como una oportunidad para enriquecer las redes de socialización de los jóvenes estudiantes. Los nuevos hábitos de movilidad abren posibilidades de interacción en nuevos lugares de la ciudad que se vuelven progresivamente significativos para los jóvenes, recuperando el sentido de habitar como 
apropiación del espacio (Martínez, 2014), en este caso, de la ciudad.

Como contrapartida, el volver diariamente a sus comunas es experimentado cada vez más como una desconexión de sus vínculos relevantes. Los jóvenes se perciben como parte de Santiago y reconocen que no solo sus amigos e intereses están y se desarrollan en el centro, sino que también es su vida la que está ocurriendo allá lejos. La lejanía es percibida como una barrera que limita el desarrollo de lo que es deseado por ellos. Así algunos de los participantes idealizan o sueñan sobre cómo sería su vida si la lejanía no fuese un tema para ellos, como ocurre con sus compañeros de otros lugares de la ciudad. Los jóvenes habitantes del periurbano realizan cambios y ajustes en su vida para mantener su conexión con los nuevos territorios, concebidos únicamente por el hecho de "vivir lejos". Para los jóvenes que han desarrollado un vínculo acotado a la satisfacción de necesidades con la centralidad esto no es percibido como injusto, sino más bien con una noción de esfuerzo y empeño personal que es condición necesaria para vivir en el periurbano. Mientras que para quienes mantienen un vínculo asociado al disfrute de necesidades y deseos, la condición de ajustar sus hábitos y actividades sí es percibido como injusto, pues sus pares no están obligados a esforzarse como ellos lo hacen, por lo que ese esfuerzo es muchas veces normalizado por otros que desconocen lo que es vivir "lejos".

Lo común a ambos es que observan las exigencias que tiene el viajar desde sus comunas como algo no modificable y, por lo tanto, no se sienten capaces de mejorar o transformar esas exigencias para hacer menos agotadora su vida cotidiana. Perciben que solo pueden hacer ajustes menores: pueden cambiar de ruta, cambiar sus horarios, desplazar actividades, pero en ningún caso creen que sea posible que, desde el periurbano, el viaje hacia otro punto de la ciudad deje de ser un problema. Esto es experimentado con frustración y agobio respecto del tiempo que les queda como estudiantes. Esta situación se profundiza en el caso de los estudiantes de Lampa, que deben además sufrir el hostigamiento constante de los choferes de buses interurbanos, manifestado en insultos, omisión de las paradas del servicio, impedimento a subir al bus, y en una narración, destrucción del pase escolar (credencial de pase rebajado estudiantil), ya sea para que viajen de pie pues pagan menos que los adultos o para obligarlos a pagar la tarifa completa.

A partir de los nuevos hábitos de movilidad adoptados, los jóvenes comienzan a experimentar un acentuado desgaste físico y mental que inhibe las actividades que realizan cotidianamente. La descripción de las dificultades del viaje se vuelve corporeizada en la narración de los jóvenes, lo que se expresa también en su postura corporal y tono de voz en las entrevistas: suspiros al iniciar o terminar las frases, la encorvadura de hombros y el cambio repentino de la mirada hacia el cielo, son elementos que repiten cada vez que los participantes comienzan a hablar sobre su movilidad.

Es desde estas tensiones en lo que significa para ellos movilizarse diariamente hacia el centro de la ciudad que los jóvenes evalúan su situación residencial. Los jóvenes que han establecido un vínculo estrecho con el centro de la ciudad perciben que sus comunas de residencia ya no les provee oportunidades para la satisfacción de las necesidades y deseos que tienen, por lo que ya planifican el cambio de residencia una vez finalizados sus estudios superiores. Por otro lado, en los jóvenes que el vínculo con el centro de la ciudad se acota a la satisfacción de necesidades de estudio, y de alguna manera se resisten a mantener más vínculos con otros territorios de la ciudad, aspiran a permanecer en sus comunas, y que una vez finalizados sus estudios superiores sus hábitos de movilidad vuelvan a ser como antes.

\section{Conclusiones}

El cambio en las experiencias de movilidad cotidiana de los jóvenes habitantes del periurbano de Lampa y Quilicura, producto de su ingreso a la educación superior, trae consigo fuertes cambios no previstos en muchas dimensiones relevantes de sus vidas, lo que se expresa, finalmente, en un extrañamiento respecto a su barrio y su comuna, la pérdida de densidad de su vida social en la escala local, la construcción de vínculos diversos y relevantes lejos de su lugar de residencia (aunque muchas veces acompañados de la frustración de no poder desarrollarlos en plenitud), y una continua sensación de desgaste y sobresfuerzo respecto a su vida cotidiana. En este sentido, este estudio confirma, para el caso de los jóvenes, la evidencia existente respecto a la pérdida de la vida social de los trabajadores que habitan en zonas periurbanas, al priorizar la realización de sus actividades funcionales a costa del tiempo de disfrute y ocio, pero con matices propios de las características de la etapa vital que les toca vivir.

Los relatos de los jóvenes oscilan entre la comprensión de su movilidad cotidiana como fuente de oportunidades para conocer e interactuar con otros jóvenes diversos, en espacios distintos a los que ofrece su propia comuna, y la descripción de la movilidad en tanto sacrificio, en 
que la intensidad del viaje se expresa en un constante cansancio físico y mental y una constante presión espacio temporal. Esta experiencia de movilidad rompe con su vivencia previa, en el período escolar, en que la movilidad cotidiana era de escala comunal, generalmente caminable, en un marco de abundancia del tiempo que permitía el uso intensivo de los espacios locales.

En términos del disfrute de las oportunidades de la vida urbana, entendido como la participación en las oportunidades que reportan efectos a la vida social de los sujetos (socialización, recreación, cultura y consumo), se observa que en estos jóvenes ese disfrute se deslocaliza desde sus comunas hacia el centro de la ciudad. Los territorios de proximidad pasan de ser el principal escenario de la vida de los jóvenes a ser una "pausa" respecto de lo que sucede allá, lejos.

Esas "pausas" que experimentan en sus comunas son percibidas también entre dos polos en los que los jóvenes oscilan. Por una parte, en sus comunas de residencia los jóvenes tienen la posibilidad de desarrollar dinámicas de inmovilidad, lo que progresivamente es altamente valorado dadas las condiciones que deben hacer frente en cada uno de sus viajes: no movilizarse puede ser sentido como una oportunidad para descansar del ritmo y actividades que actualmente desarrollan. En contraposición a ello, se encuentra la percepción de que esas "pausas" les reportan una desconexión de todo lo que desarrollan en las áreas centrales, por lo que se sienten aislados de aquello que es importante para ellos.

No hay que perder de vista que estos cambios se producen en el marco del ingreso a la educación superior, una etapa en la que los jóvenes se encuentran en proceso de definición sus propios proyectos de vida. Los participantes del estudio reconocen que el disfrutar lo que están estudiando es lo que lo motiva a viajar regularmente al centro de la ciudad y soportar el viaje. Además, valoran las nuevas amistades y redes de contacto que han formado, y que les han permitido conocer realidades diversas, algunas de ellas inexistentes en sus comunas. Cuanto más identificados se declaran con lo que la vida urbana les ha ofrecido, más oportunidades perciben: ya sea en materia de estudios, oportunidades laborales, recreativas, y de consumo; y dado eso, más buscan acceder a ellas. Los jóvenes que menos identificados se sienten con esa oferta, buscan acceder solo a las oportunidades que son de su interés, aunque perciban que hay más en el centro de la ciudad. Sin embargo, para ambos su acceso se percibe mediado por las posibilidades que el sistema de transporte público les ofrece.
El sistema de transporte en la Región Metropolitana en áreas periurbanas tiene menos alcance y frecuencia que en áreas pericentrales de la ciudad, y esto impacta en las actividades que los jóvenes pueden desarrollar en el centro, pues deben planificar su día en función de ello, y no al revés, como se podrían sostener desde el enfoque de movilidad justa, en el que es el Estado y el sistema de transporte son quienes garantizan a sus ciudadanos el acceso y satisfacción de sus necesidades de movilidad (Blanco \& Apaolaza, 2017).

En los jóvenes entrevistados emergen con fuerza las tensiones espaciotemporales que supone el residir en el periurbano y desarrollar parte importante de la vida en las áreas centrales de la ciudad, lo que inevitablemente en todos los casos revisados en este estudio ha implicado la adaptación de la dimensión social de su vida para poder mantener los hábitos de movilidad que exige su continuidad de estudios. Lamentablemente, también en todos los casos se manifiesta una fuerte frustración en la medida en que los jóvenes no sienten que tengan la capacidad de mejorar su situación de movilidad: no hay nada que ellos sientan que puedan hacer para cambiar su viaje, pese todas las consecuencias que este tiene en sus vidas. El viaje cotidiano emerge, entonces, como posibilidad de ejercer su derecho a la ciudad, y simultáneamente, como una dimensión de desigualdad urbana.

\section{Referencias}

Andreasen, M. H., \& Møller-Jensen, L. (2017). Access to the city: Mobility patterns, transport and accessibility in peripheral settlements of Dar es Salaam. Journal of Transport Geography, 62, 20-29. https://doi. org/10.1016/j.jtrangeo.2017.05.005

Apaolaza, R., Blanco, J., Lerena, N., López Morales, E., Lukas, M., \& Rivera, M. (2016). Transporte, desigualdad social y capital espacial: análisis comparativo entre Buenos Aires y Santiago de Chile. Íconos, Revista de Ciencias Sociales, 56, 19-41. https://doi.org/10.17141/iconos.56.2016.2148

Blanco, J. \& Apaolaza, R. (2017). Socio-territorial inequality and differential mobility. Three key issues in the Buenos Aires Metropolitan Region. Journal of Transport Geography, 67, 76-84. https://doi. org/10.1016/j.jtrangeo.2017.07.008

Blanco, J., Bosoer, L. \& Apaolaza, R. (2014). Movilidad, apropiación y uso del territorio: una aproximación a partir del caso de Buenos Aires. Scripta Nova. 
Revista Electrónica de Geografía y Ciencias Sociales, 18(493), 1-17.

Büscher, M. \& Urry, J. (2009). Mobile methods and the empirical. European Journal of Social Theory, 12(1), 99-116.

Brunet, I. \& Pizzi, A. (2013). La delimitación sociológica de la juventud. Última década, 21(38), 11-36. https:// doi.org/10.4067/S0718-22362013000100002

Calonge, F. (2017). Estar cerca en la lejanía. El surgimiento de los entornos de vida en una periferia. Athenea Digital. Revista de Pensamiento e Investigación Social, 17(2), 149-173. https://doi. org/10.5565/rev/athenea. 1761

Clark, A. \& Emmel, N. (2010). Using walking interviews. Realities Toolkit, 13, 1-6. Recuperado de: http://eprints.ncrm.ac.uk/1323/1/13-toolkit-walkinginterviews.pdf

Córdoba, C. (2014). La elección de escuela en sectores pobres: Resultados de un estudio cualitativo. Psicoperspectivas, 13(1), 56-67. https:// dx.doi.org/10.5027/psicoperspectivas-Vol13-Issue1fulltext-301

Córdoba, C., Farris, M. \& Rojas, K. (2017). Discussing school socioeconomic segregation in territorial terms: the differentiated influence of urban fragmentation and daily mobility. Investigaciones geográficas, 92, 34-50. https://dx.doi.org/10.14350/rig.54766

Cornejo, M., Mendoza, F. \& Rojas, R. (2008). Research with Life Stories: Clues and Options of the Methodological Design. Psykhe (Santiago), 17(1), 29-39. https://dx.doi.org/10.4067/S071822282008000100004

Cosacov, N. (2015). Más allá de la vivienda: los usos de la ciudad: Movilidad cotidiana de residentes en Buenos Aires. Estudios Socioterritoriales, 18, 61-80.

Cresswell, T. (2010). Towards a politics of mobility. Environment and planning $D$ : society and space, 28(1), 17-31. https://doi.org/10.1068/d11407

De Haas, M. C., Scheepers, C. E., Harms, L. W. J., \& Kroesen, M. (2018). Travel pattern transitions: applying latent transition analysis within the mobility biographies framework. Transportation Research Part A: Policy and Practice, 107, 140-151. https:// doi.org/10.1016/j.tra.2017.11.007

Delclòs-Alió, X. \& Miralles-Guasch, C. (2017). Suburban travelers pressed for time: Exploring the temporal implications of metropolitan commuting in Barcelona. Journal of Transport Geography, 65, 165174. https://doi.org/10.1016/j.jtrangeo.2017.10.016

Donoso-Díaz, S. \& Arias-Rojas, O. (2013). Desplazamiento cotidiano de estudiantes entre comunas de Chile: evidencia y recomendaciones de política para la nueva institucionalidad de la Educación Pública. EURE (Santiago), 39(116), 39-73. https:// dx.doi.org/10.4067/S0250-71612013000100002

Döring, L., Albrecht, J., Scheiner, J. \& Holz-Rau, C. (2014). Mobility biographies in three generationssocialization effects on commute mode choice. Transportation Research Procedia, 1(1), 165-176. https://doi.org/10.1016/j.trpro.2014.07.017

Elacqua, G. \& Fabrega, R. (2004). El consumidor de la educación: El actor olvidado de la libre elección de escuelas en Chile. Santiago de Chile: PREAL. Recuperado de: http://www.opech.cl/bibliografico/ Doc_Financiamiento/consumidor_educacion.pdf

Flick, U. (2007 ). Introducción a la investigación cualitativa. Madrid: Ediciones Morata.

Flores, C. (2006). Consecuencias de la segregación residencial: Teoría y métodos. En J.M.Cunha (Comp.), Metrópoles paulistas: População, vulnerabilidade e segregação (pp. 197-230). Campinas: Nepo.

Gil, E. (2009). Trayectorias y transiciones: ¿qué rumbos? Revista de Estudios de Juventud, 87, 15-30.

Gouëset, V., Demoraes, F., Le Roux, G., Figueroa, O. \& Zioni, S. (2015). Recorrer la Metrópoli. Prácticas de movilidad cotidiana y desigualdades socioterritoriales en Bogotá, Santiago de Chile y São Paulo. En Dureau F., Lulle T., Souchaud S. \& Contreras Y. (Eds.), Movilidades y cambio urbano. Bogotá, Santiago y São Paulo (pp. 303-344). Recuperado de https://hal.archives-ouvertes.fr/hal-01282075

Guzmán, L. A., Oviedo, D. \& Rivera, C. (2017). Assessing equity in transport accessibility to work 
and study: The Bogotá region. Journal of Transport Geography, 58, 236-246, https://doi.org/10.1016/j. jtrangeo.2016.12.016

Harvey, D. (2013). Ciudades rebeldes: del derecho de la ciudad a la revolución urbana. Madrid: Ediciones Akal.

Hernández, D. (2012). Activos y estructuras de oportunidades de movilidad: Una propuesta analítica para el estudio de la accesibilidad por transporte público, el bienestar y la equidad. EURE (Santiago), 38(115), 117-135. http://dx.doi. org/10.4067/S0250-71612012000300006

Hernandez, D. (2018). Uneven mobilities, uneven opportunities: Social distribution of public transport accessibility to jobs and education in Montevideo. Journal of Transport Geography, 67, 119-125. https:// doi.org/10.1016/j.jtrangeo.2017.08.017

Imilan, W. \& Jirón, P. (2018). Moviendo los estudios urbanos. La movilidad como objeto de estudio o como enfoque para comprender la ciudad contemporánea. Quid 16: Revista del Área de Estudios Urbanos, 10, 17-36.

Imilan, W., Jirón, P. \& Iturra, L. (2015). Más allá del barrio: Habitar Santiago en la movilidad cotidiana. Revista Antropologías del Sur, 2(3), 87103.

Iturra, L. \& Jirón P. (2016). Siguiendo trayectorias, dibujando trayectos. Construcción de diagramas desde la experiencia de los habitantes. Revista AUS, 19, 4-9. https://doi.org/10.4206/aus.2016.n19-02

Janoschka, M. (2002). El nuevo modelo de la ciudad latinoamericana: fragmentacióny privatización. EURE (Santiago), 28(85), 11-20. https://dx.doi.org/10.4067/ S0250-71612002008500002

Jirón, P. (2017). El hábitat residencial observado desde la movilidad cotidiana urbana. En: Imilan, W., Larenas, J., Carrasco, G. y Rivera, S. (Eds.), ¿Hacia dónde va la vivienda en Chile?: nuevos desafios en el hábitat residencial (pp. 269-279). Santiago de Chile: INVI, MINVU, Adrede.

Jirón, P. \& Lange, C. (2017). Comprender la ciudad desde sus habitantes. Cuestiones de Sociología, 16, 1-12. https://doi.org/10.24215/23468904e030.
Kenyon, S., Lyons, G. \& Rafferty, J. (2002). Transport and social exclusion: investigating the possibility of promoting inclusion through virtual mobility. Journal of Transport Geography, 10(3), 207-219. https://doi. org/10.1016/S0966-6923(02)00012-1

Landon,P.(2013). Movilidad cotidiana y exclusión social: anverso y reverso de la instalación de la autopista acceso sur en la periferia pobre de la metrópolis de Santiago de Chile. Encuentro Iberoamericano de Movilidad Urbana Sostenible (EIMUS). Recuperado de http://www.ciudadenmovimiento.org/wp-content/ uploads/2014/03/3er-Premio-Paulette-Landon.pdf

Lazo, A. \& Calderón, R. (2014). Los anclajes en la proximidad y la movilidad cotidiana: Retrato de tres barrios de la ciudad de Santiago de Chile. EURE (Santiago), 40(121), 121-140. https://dx.doi. org/10.4067/S0250-71612014000300006

Mansilla, P. (2018). Transformaciones Socio Territoriales en el Periurbano y Desigualdad Espaciotemporal. Revista ESPACIOS, 39(16), 27.

Martínez, E. (2014). Configuración urbana, hábitat y apropiación del espacio. Scripta Nova. Revista Electrónica de Geografía y Ciencias Sociales, 18.

Martínez, F., Hodgson, F., Mullen, C. \& Timms, P. (2017). Creating inequality in accessibility: The relationships between public transport and social housing policy in deprived areas of Santiago de Chile. Journal of Transport Geography, 67, 102-109. https://doi.org/10.1016/j.jtrangeo.2017.09.006

Millán, R. (2010). Los efectos de la geografía de oportunidades sobre las preferencias de movilidad residencial al interior de barrios populares consolidados en Santiago de Chile (1990-2010) (Tesis de Magíster, Pontificia Universidad Católica de Chile, Santiago, Chile).

Ministerio de Educación [MINEDUC]. (2018). Oferta Académica [Base de datos], Servicio de Información de Educación Superior (SIES). Recuperado de https:// www.mifuturo.cl/wp-content/uploads/2019/01/ OFICIAL_OA_2019_21_01_2019_V1.csv. zip? 78460

Müggenburg, H., Busch-Geertsema, A. \& Lanzendorf, M. (2015). Mobility biographies: A review of achievements and challenges of the mobility 
biographies approach and a framework for further research. Journal of Transport Geography, 46, 151163. https://doi.org/10.1016/j.jtrangeo.2015.06.004

Nikolaeva, A., Adey, P., Cresswell, T., Lee, J., Novoa, A. \& Temenos, C. (2018). A new politics of mobility: Commoning movement, meaning and practice in Amsterdam and Santiago. Faculty of Social and Behavioral Sciences (FMG) Centre for Urban Studies Working Paper Series, 26, 3-33. Recuperado de https://rgs-ibg.onlinelibrary.wiley.com/doi/ full/10.1111/tran.12287

Sattlegger, L., \& Rau, H. (2016). Carlessness in a carcentric world: A reconstructive approach to qualitative mobility biographies research. Journal of transport geography, 53, 22-31. https://doi.org/10.1016/j. jtrangeo.2016.04.003

Saraví, G. (2006). Biografías de exclusión: desventajas y juventud en Argentina. Perfiles Latinoamericanos, $28,83-116$.

Solanilla, M. U. (2007). La sociología de la juventud revisitada. De discursos, estudios, e "historias" sobre los "jóvenes". Intersticios. Revista sociológica de pensamiento crítico, 1(2).

Urcola, M. (2003). Algunas apreciaciones sobre el concepto sociológico de juventud. Invenio: Revista de investigación académica, 11, 41-50.

Velázquez, M. (2018). Derecho a la movilidad. En Zunino, D., Giucci, G. y Jiron, P. (Eds.), Términos clave para los estudios de movilidad en América Latina. Buenos Aires: Biblos.

Verlinghieri, E. \& Venturini, F. (2018). Exploring the right to mobility through the 2013 mobilizations in Rio de Janeiro. Journal of Transport Geography, 67, 126136. https://doi.org/10.1016/j.jtrangeo.2017.09.008 